\title{
Lyme Borreliosis: From Etiological Agent to Human Pathogenesis
}

\author{
Violeta BRICIU ${ }^{1,2, *}$ \\ ${ }^{1}$ Department of Infectious Diseases, University of Medicine and Pharmacy „Iuliu Hațieganu”, Str. Victor \\ Babeș Nr. 8, 400012, Cluj-Napoca, Romania \\ ${ }^{2}$ Clinic of Infectious Diseases, Str. Iuliu Moldovan Nr. 23, 400348, Cluj-Napoca, Romania \\ Corresponding author: briciu.tincuta@umfcluj.ro
}

Bulletin UASVM Veterinary Medicine 72(1) / 2015,

Print ISSN 1843-5270; Electronic ISSN 1843-5378

DOI:10.15835/buasvmcn-vm: 11063

\begin{abstract}
Lyme borreliosis, a multisystem disorder, is caused by spirochaetes of the Borrelia (B.) burgdorferi sensu lato complex, which are transmitted by ticks. In the last years the disease has become a global public health problem and a prototype of an emerging infection. This review presents a large body of information on cellular and molecular biology of B. burgdorferi, interaction with the human host, immune response and disease pathogenesis.
\end{abstract}

Keywords: Borrelia burgdorferi sensu lato, Lyme borreliosis, pathogenesis.

\section{INTRODUCTION}

Lyme borreliosis (LB), a tick borne disease with the highest incidence in Europe and North America, is a zoonosis; Borrelia burgdorferi sensu lato, the etiological agent, circulates between the Ixodes ricinus complex ticks and a variety of vertebrate hosts like rodents, squirrels and many species of birds. Natural hosts do not appear to develop clinical disease, while in humans LB presents with a variety of clinical signs and symptoms, affecting the skin, the heart, the nervous and musculoskeletal systems, and several variations in the course of the disease. LB has been first described in 1977 in the United States, though documentations of the disease exist from the end of the XIX ${ }^{\text {th }}$ century in Europe. Recent molecular studies have identified sequence of $B$. burgdorferi DNA in "the Iceman" from Tyrol, a 5300 years old human body discovered in the Alps (Keller et al., 2011). As in the last years the disease has become a global public health problem and the interest of medical personnel and researchers is constatly increasing, the review presents information on cellular and molecular biology of B. burgdorferi, interaction with the human host, immune response and disease pathogenesis.

\section{THE ETIOLOGY OF LYME BORRELIOSIS}

The first description of LB was made in Germany in 1883 as a chronic dermatological disease, named acrodermatitis chronica atrophicans (ACA). In 1909, the Swedish dermatologist Afzelius described a slowly expanding cutaneous lesion, named erythema migrans (EM) and in 1930 Hellerstrom suggested a relationship between tick bite, EM and disorders of the nervous system. In 1975-1976 in the town of Lyme, USA, cases of arthritis in children were described, characterized by debut in summer or autumn, short and recurrent attacks of tumefaction and pain in the large joints, preceded by a skin rash. This new entity was named Lyme arthritis, but in the following years a multisystemic disorder was described, named Lyme disease and later, after the discovery of the etiological agent, Lyme borreliosis (Burgdorfer et al., 1982).

In 1982 Burgdorferi described a spirochete of the genus Borrelia in the body of the Ixodes ticks, identified as the etiological agent of LB and named Borrelia burgdorferi. Due to the development of new molecular diagnostic tools, new species of $B$. burgdorferi were described in the following years; 
nowadays 19 different species are identified with different geographical distribution (Franke et al., 2013).

The genus Borrelia, a member of the spirochaete phylum, is divided into three major pathogenic groups of organisms, all transmitted by arthropods: B. burgdorferi sensu lato (the agent of LB), the relapsing fever borreliae, and the etiological agent of avian spirochaetosis, Borrelia anserina. Members of the genus Borrelia have a very complex lifestyle as they are host associated spirochaetes that shuttle between haematophagous arthropods and vertebrates.

\subsection{Morphology, Shape and Membrane Structure}

B. burgdorferi is a thin, elongated, motile, wave-like bacteria with the diameter of $0.2 \mu \mathrm{m}$ and length of $15 \mu \mathrm{m}$. The bacterium has a fragile outer membrane surrounding the protoplasmic cylinder. This cylinder consists of a peptidoglycan layer, a cytoplasmic membrane (inner membrane) and the enclosed cytoplasmic contents (Johnson et al., 1984). 7-11 bipolar flagella are located in the periplasmic space attached to the poles and wrapped around the cell cylinder, giving the bacterium its characteristic flat wave shape (Motaleb et al., 2000).

\subsubsection{Flagella, motility and chemotaxis}

The periplasmic flagella, with an important role in morphology and motility, presents a filament, a hook and basal body, but it is composed by two classes of proteins, instead of one as in other bacteria. The external flagellar protein Fla A is characteristic to the spirochetes, while Fla $B$ presents homology to the flagellar proteins of other bacteria. A feature of B. burgdorferi s.l. is its capacity to swim efficiently in a viscous medium such as the connective tissue where other bacteria are slowed down or immobilized.

\subsubsection{Structure of the outer membrane}

Since B. burgdorferi s.l. possesses both an outer membrane and a cytoplasmic membrane, the surface of this bacterium is analogous to enteric Gram-negative bacteria, but it has also several distinct features. For example, $B$. burgdorferi s.l. has a high abundance of membrane proteins covalently modified with lipids, has no lipopolysaccharide (LPS) but presents glycolipid antigens other than LPS. The $B$. burgdorferi outer membrane contains a low density of transmembrane-spanning proteins, being more susceptible to disruption by routine physical manipulations and to detergents compared with Gram-negative bacteria (Bergström et al., 2002).

\section{A. The lipoproteins}

While the spirochete passes from the arthropod to the vertebrate, there are changes from an environment with no immune system based on antibodies to an environment with high immunological pressure. To persist in its host, $B$. burgdorferi changes its surface antigens. More than 100 polypeptides have been identified in the outer membrane, but the sequencing of $B$. burgdorferi genome has defined many other hypothetical lipoproteins. The most studied are the major outer surface proteins (Osps). Until now 6 Osps have been characterised, OspA-F, exposed to the surface and fixed through a lipidic fraction to the external membrane.

The first B. burgdorferi gene sequenced, osp $A$, encodes the most studied protein of the bacteria. OspA is expressed by the spirochete in the midgut of unfed tick and mediates binding to the intestinal epithelium. OspA and OspB are implied also in the adherence and penetration of the mammalian host cell, having a role in the pathogenesis of LB. OspC is very heterogenic, 19 major OspC groups being identified. The expression of OspA and OspB decreases while the tick is feeding. OspC expression is induced 36-48 hours after the blood meal starts and mediates the escape of the spirochaete from the tick midgut via the haemolymph to the salivary glands from where it enters the new vertebrate host. OspD is another component of the outer membrane, while OspE and OspF are the founding members of a protein family known as the OspEF-related proteins (Erps), important for the virulence of $B$. burgdorferi (they bind complement factor $\mathrm{H}$ and inhibit complement activation). Recombination of the genes encoding the Erp antigens might contribute to the evasion of the mammalian immune response.

The decorin-binding proteins. Microbial adhesion and colonization of host tissues are important events in the bacterial infection process. Spirochaetes injected in the skin are found associated with collagen fibres in the extracellular matrix, but they do not attach directly to collagen but to decorin, a small proteoglycan. There are two borrelial-encoded adhesins that can bind to decorin, DbpA and $\mathrm{DbpB}$ (decorin-binding protein), and a protein that can bind fibronectin- 
BBK32. The interaction between BBK32 and fibronectin seems to be an important pathogenic mechanism for dissemination and persistence of B. burgdorferi into the mammalian host.

The vmp-like sequence, Vls, of $B$. burgdorferi s.l. Persistence of $B$. burgdorferi in the host can be achieved by a mechanism called antigenic variation; this mechanism has been studied for several years in relapsing fever borreliosis where new serotypes appear during relapses due to a change in surface proteins called variable major proteins (Vmps). In B. burgdorferi s.s a linear plasmid was found to have a sequence that resembles the Vmp system in B. hermsii - vls locus. Recombination occurs in vivo as early as 4 days after experimental infection of mice but not in vitro, suggesting that the mammalian host provides the signal for $v l s$ recombination (Zhang and Norris, 1998).

RevA protein. Another surface expressed protein, revA is expressed in the mammalian host due to increase in temperature $\left(36^{\circ} \mathrm{C}\right.$ compared to $23^{\circ} \mathrm{C}$ in ticks). The expression of RevA is also influenced by the $\mathrm{pH}$ (Caroll et al., 2001).

The exported plasmid protein A $(\operatorname{epp} A)$ genes are only expressed during infection in the mammalian host. The widespread occurrence of eppA suggests that they contribute to the survival of $B$. burgdorferi s.l. in nature, and possibly to the pathogenesis of LB (Miller et al., 2000).

BmpA, BmpB, BmpC and BmpD constitute a family of homologous lipoproteins that are immunogenic during infection in vertebrate hosts and BmpA (p39) is widely used in the diagnostic assays. BmpA activates the proinflammatory response in the human synovial cells (Yang et al., 2008).

\section{B. The porins}

The permeability of the bacterial cell envelopes is the result of channel forming proteins in their outer membranes, called porins. Their function is to uptake the substances from the environment. Borrelia are limited in their metabolic and biosynthetic capacities and therefore highly dependent on nutrients provided by their hosts. Tree porins have been described in B. burgdorferi: P13, P66 (Oms66) and Oms 38/ Dip A. DipA protein, which exhibits high homology to the Oms38 porin of relapsing fever Borrelia, presents a binding site specific for dicarboxylates which play important roles in the deficient metabolic and biosynthetic pathways of Borrelia species (Bergstrom and Zuckert, 2010).

\section{The envelope-spanning protein complexes}

Efflux systems and transporters. A system called BesC was identified in the outer membrane of $B$. burgdorferi with properties of efflux system and export through membrane, that was shown to be necessary for infection in mice and involved in resistance to antibiotics. This efflux system has a role in maintenance of cellular homeostasis, export of exogenous toxic agents and survival in different host environments (Bunikis et al., 2008). Glucose is the major energy source for B. burgdorferi, involving several glucose transporters. Mannose host proteins are also a carbohydrate source for B. burgdorferi, with BB0408 and BB0629 proteins suggested to be mannose transporters (von Lackum and Stevenson, 2005).

The oligopeptide permease (Opp A-1, 2 and 3) are used for transportation of peptides into bacteria, as carbon and nitrogen sources.

\subsubsection{Blebs and cysts formation}

B. burgdorferi s.l. when grown on stress culture media (antibiotics, low $\mathrm{pH}$ ) is capable of producing extracellular vesicles (blebs), that contain an outer membrane, while some also contain cytoplasmic membrane (Radolf et al., 1994). The cyst formation is a response to starvation in serum-free medium and it implies changes in the cell integrity and form (Alban et al., 2000). It is a slow but active process that needs protein synthesis, reversible in $50 \%$ of the cases. It is not known if cyst formation is implied in the persistence of $B$. burgdorferi in the host, with a role in pathogenesis, immune evasion and/or resistance to antibiotics (Brorson and Brorson, 2006; MacDonald, 2006).

\subsection{The Genome and Genome Organization}

The genetic organization of $B$. burgdorferi is unusual in the sense that it contains a small linear chromosome and 21 linear and circular plasmids (most bacterial species present a circular chromosome and circular plasmids). Most of the genome of the B. burgdorferi sensu stricto (s.s) strain B31 was published in 1997 (Fraser et al., 1997) and it was completed in 2000 (Casjens et al., 2000), with a genome size of $1.52 \mathrm{Mbp}$ : 910725 bp on the linear chromosome, and $611 \mathrm{kbp}$ divided on 12 linear (lp) and 9 circular plasmids (cp), and only 1283 genes (compared with the 4405 genes present in $E$. coli). The small number of genes in 
B. burgdorferi s.s is similar to the number of genes in the related spirochaete Treponema pallidum; a number of genes encoding cellular biosynthetic enzymes are missing. The genome of 14 strains of $B$. burgdorferi s.s. was completed till now (Casjens et al., 2000; Schutzer et al., 2011), B. afzelii, B. garinii, $B$. bissettii, $B$. valaisiana and $B$. spielmanii (Schutzer et al., 2012).

\subsection{B. burgdorferi Sensu Lato Complex}

The 19 different genomic species of $B$. burgdorferi are classified based on their pathogenicity to humans.

\subsubsection{Borrelia Species Pathogenic for Humans}

B. burgdorferi sensu stricto (s.s). In USA it is the only human pathogenic species, associated mainly to the musculoskeletal manifestations of LB, but also to the cutaneous and neurological manifestations. In Western Europe it is the species mainly isolated from arthritis (Jaulhac et al., 2000).

B. garinii. 6 serotypes have been described using monoclonal antibodies, out of which serotype 4 has been further classified as a different genospecies, B. bavariensis (Margos et al., 2009). Concerning the organotropism of $B$. garinii, the neural apparatus is the main target (Wilske et al., 1996), but rarely B. garinii has been isolated from the synovial fluid (Fingerle et al., 2008), or even from the cutaneous lesions of ACA.

B. afzelii has an organotropis for skin, being the etiological agent mainly isolated from ACA (Lünemann et al., 2001), but it was also isolated from the cerebrospinal fluid (CSF) or joints.

B. spielmanii. Until now it was isolated only from the EM lesion (Maraspin et al., 2006); it is not clear if it has an invasive potential.

B. bissettii. In Europe it was rarely isolated from the EM lesions (Strle et al., 1997), from the cardiac valve tissue (Rudenko et 2008), from the serum of some patients with the suspicion of LB (Rudenko et. 2009), or from the CSF (Fingerle et al., 2008).

B. valaisiana. The pathogenic potential has rarely been described, being isolated by polymerase chain reaction (PCR) from skin (Rijpkema et al., 1997), CSF (Diza et al., 2004), but it was not isolated by cultivation from humans.

B. lusitaniae has been isolated from the skin of a portuguese patient (de Franca et al., 2005).

2.3.2. B. burgdorferi species with no proven human pathogenic potential
Eleven species have not been isolated from human so far: $B$. americana, $B$. andersonii, $B$. californiensis, B. carolinensis, B. japonica, B. tanukii, B. turdi, B. sinica, B. yangtze, B. kurtenbachii and B. finlandensis.

Several strains of unclear phylogenetic identity still need to be characterized and, if applicable, defined as new species (Franke et al., 2013).

\subsubsection{B. burgdorferi species in Romania}

B. afzelii, B. garinii, B. burgdorferi s.s., $B$. valaisiana and $B$. lusitaniae, species with human pathogenical potential, have been identified in Romania in questing ticks (Kalmár et al., 2013) and in ticks collected from humans or animals (Briciu et al., 2014; Ionita et al., 2013).

\section{EPIDEMIOLOGY OF LB}

\subsection{Terminology}

A vector tick is able to acquire the pathogen during the blood meal, maintains it through one or more life stages and passes it on to other hosts when feeding again. In rare cases uninfected ticks can also acquire an infection when feeding together - "co-feeding"- with infected vector ticks on a host, when mating, or the female infects transovarian the eggs.

Tick hosts include all vertebrates that ticks feed on in nature. A reservoir host must take up a critical number of infectious agents during an infectious tick bite, must allow the pathogen to multiply and to survive in its body and must allow the pathogen to find its way into other feeding ticks. Non-reservoir hosts may have contact with infected ticks and may or may not develop a longlasting infection but are incapable of transmitting the infection to ticks. Barrier hosts eliminate the infection in feeding ticks (zooprophylactic host), or destroy a large numbers of vector ticks because of efficient grooming or an acquired anti-tick immunity (Kahl et al., 2002).

\subsection{Vectors}

Ticks are classified in the class Arachnida, subclass Acari, order Parasitiformes, and suborder Ixodida. There are approximately 878 species, divided into four families, specifically the Argasidae (soft-bodied ticks), Ixodidae (hard-bodied ticks), Nutalliellidae, and Laelaptidae (Anderson JF, Magnarelli, 2008). The identification of ticks uses a holistic system (Estrada-Peña et al., 2004).

I. ricinus, the most important vector of $B$. burgdorferi in Europe, has a life cycle between 2-6 
years (it may vary from one habitat to another, influenced by climatic factors). The stages of development are represented by eggs, larva, nymphs and adults. I. persulcatus, the taiga tick is the vector of LB in the southern forest zone of Eurasia and some countries from Asia. I. ricinus and I. persulcatus overlap in far-eastern Europe. In the East and Center of North America the main vectors are I. scapularis ticks, while I. pacificus is the main vector in the Western regions, along the Pacific coast.

B. burgdorferi s.l., ingested with the blood meal, colonize the mid-gut of the tick and persist there along the different stages of development (trans-stadial transmission).

\subsection{Reservoir hosts}

At least 237 animal species are implied in the maintenance of $I$. ricinus population and are susceptible to be reservoir hosts for $B$. burgdorferi (Gern, 2008). The xenodiagnosis, the only way to prove the infectivity of a vertebrate species, implies capturing and keeping in captivity the vertebrate. The reservoir host does not develop the disease, though minor symptoms may be present. It was proved that rodents, squirrels and many species of birds are reservoir hosts. Out of the large mammals, the red foxes are reservoir hosts while large ungulates are not, but they contribute indirectly to spirochetes transmission, being hosts for ticks. Migratory birds play a key role for LB distribution, since they are not only a reservoir for important Borrelia spp., but they also act as vehicles of infected ticks over long distances (Rudenko et al., 2011). The description of new species of Borrelia in the last years has opened a new domain in LB ecology that suggests an association between certain genospecies and vertebrate hosts.

\section{B. BURGDORFERI INTERACTION WITH THE HOST}

\subsection{The Bite Site}

The tick creates a feeding pit with its mouthparts, using its hypostome (a barbed protuberance) as an anchor to the skin of the host, while bioactive agents from tick saliva are inoculated into the skin that increase $B$. burgdorferi chances of survival (Radolf et al., 2012). Proteins BbCRASPs (B. burgdorferi complement regulatoracquiring surface proteins) bind complement factor $\mathrm{H}$ and complement factor Hlike protein
1. The first recognition of $B$. burgdorferi by the mammalian host is performed by the dendritic cells and macrophages in the dermis. Production of cytokines and chemokines by neutrophils results in the recruitment of additional inflammatory cells to the bite site. B. burgdorferi is a very motile organism that may escape from these phagocytes (Moriarty et al., 2008); the spirochetes that do not escape are ingested and degraded into the phagosomes. Dendritic cells that have taken up spirochaetes migrate to the lymph nodes, where they present processed borrelial antigens to $\mathrm{T}$ cells and B cells. Sensitized T cells enter the circulation and are recruited to the site of infection. Plasma cells secrete specific antibodies that can kill $B$. burgdorferi via complement-dependent and -independent pathways.

\subsection{Dissemination}

After a delay of up to 2 days, B. burgdorferi begins to spread to distant tissues. To disseminate, $B$. burgdorferi penetrates the matrix between cells and enters capillary beds. The spirochaete circumvents its inability to produce enzymes capable of digesting extracellular matrix components by appropriating host proteases, such as plasminogen and urokinase. Egress from the circulation into tissues involves adhesion to vascular endothelium, followed by extravasation and expression of several adhesins that mediate attachment to host tissue.

\subsection{Immune Response}

Both the innate and adaptive immune systems are important for controlling infection during the disseminated phase, as mice that are deficient in either system have greater bacterial burdens than wild-type mice (Weis and Bockenstedt, 2010). The early development of IgM antibodies independent of $\mathrm{T}$ cells is crucial for clearing the pathogen. $\mathrm{T}$ cell-dependent production of IgG by B cells is detectable later during infection.

The need for serological tests to diagnose LB has led to increased research on the immune response during $B$. burgdorferi infection. Flagellin $B$ induces an early and intense response in antibodies, but has the disadvantage of crossreactivity with antigens of other bacteria. OspC induces an intense immune response early during infection but presents a heterogeneity of epitopes in the differentstrains. In spite of its role in antigenic variation, VlsE presents a highly immunogenic epitope both in early and late infection, being used 
in diagnostic assays. The IgM and IgG antibodies develop slowly, directed towards a large number of proteins, as long as infection progresses. The first appear the antibodies against flagellin (FlaB) and p66, followed, as B. burgdorferi disseminates in the host, by antibodies anti OspC, VlsE, BBK32, Fla A, BmpA (Wilske et al., 2007).

As almost half of the patients with EM do not present detectable antibodies, the lack of serological response does not exclude the diagnostic of EM (Dandache and Nadelman, 2008). The existing data show an unpredictable response in antibodies after therapy, variable and not correlated with clinical evolution (Glatz et al., 2006). The persistence of IgM and IgG antibodies has been described 10-20 years after infection in asymptomatic patients (Kalish et al., 2001). It is assumed that the sustained positive titers indicate a long-term serologic memory that results from an antigen-independent polyclonal activation and differentiation of memory B cells. IgG antibodies are found in high titers in patients with Lyme arthritis.

\subsection{Immune Evasion}

Antigenic variation (VlsE) represents the main mechanism for infection in mammalian hosts (Bankhead and Chaconas, 2007).

Inhibition of complement cascade. Through BbCRASP Borrelia binds the factor $\mathrm{H}$ proteins and inhibits the binding of active $\mathrm{C} 3 \mathrm{~b}$ on its surface, protecting the bacterium against complementmediated killing (Kraiczy et al., 2001).

Protective niches. B. burgdorferi may survive for at least one year in the tissue of experimentally infected mice, and due to its motility and invasiveness, it may penetrate in the conjunctive tissue (Cabello et al., 2007). Though in vitro data have shown that $B$. burgdorferi may survive in intracellular niches (Girschick et al., 1996), in vivo spirochetes have been visualized only extracellular. New studies are needed to sustain the role of niches in persistent infection.

\subsection{Persistence of Infection}

$B$. burgdorferi has the particularity of an extracellular pathogen that can cause persistent infection. Although there are many studies that suggest the role of immune response in controlling infection, in some tissues, like joints, the evasion of the immune response may be explained by the affinity of the spirochetes to the relatively avascular conjunctive tissue, that could impede the penetration of phagocytes, antibodies or even antibiotics. The persistence of spirochetes in the vascular cutaneous tissue of immunocompetent mouse, visualizing the spirochetes without an associated immune infiltrate, is rather difficult to explain (Hodzic et al., 2003). An explanation could be that in this "dormant" phase the spirochetes are "seen" as harmless by the immune system, possibly hiding under the host's proteins or diminishing the antigen expression or proinflammatory molecules. Another explanation could be that spirochetes in the persistent phase of infection induce changes in the environment, that suppress the recruitment of inflammatory cells. Embers et al. (2012) evaluated the primates Rhesus macaque laboratory infected with $B$. burgdorferi, proving by xenodiagnosis post-therapeutical persistence of $B$. burgdorferi. The persistence of $B$. burgdorferi was proved in mice and dogs (Straubinger et al., 1997; Hodzic et al., 2008), but no Borrelia transmission to naive mice was achieved from ticks that fed on the infected mice. It was suggested that the persistent spirochetes are attenuated and noninfectious, representing a subpopulation of persisters tolerant to antibiotics. The persistence of $B$. burgdorferi in the host and the resistance to antibiotics was suggested by some authors to be due to a phenotypic resistance and cyst formation (Hunfeld et al., 2006; Sapi et al., 2011) or to a biofilm (Sapi et al., 2012). New studies are needed to support these theories. The main questions regarding $L B$ are that if the spirochetes remain pathogen after antibiotic therapy, if they will persist for a long time or if they will be cleared by the immune response of the host.

\subsection{Reinfection}

It was shown that human immune response is not protective against reinfection in patients with EM treated with antibiotics. Reinfection, clinically manifested as different EM lesions at different moments, is described in patients with repeated tick bites, but seems to be extremely rare in patients with late manifestations (i.e. arthritis). In case of late manifestations, sustained immune response seems to offer a better protection against reinfection. It is not known yet if immunosupression increases the risk of reinfection. The variability of different strains may explain the escape from the existent immune response after a previous infection, followed by reinfection (Nadelman and Wormser, 2007). 


\section{PATHOGENESIS}

$B$. burgdorferi genome does not encode any known toxins; tissue damage, and hence disease, is believed to be caused by multiplication, invasion, persistence of $B$. burgdorferi and to the inflammatory response elicited in the mammalian host. Data regarding the pathogenesis of LB has been obtained from studies on mice, seldom on dogs or monkeys, and a few studies on human cutaneous or synovial tissue, cerebrospinal or synovial liquid. The biopsies of EM lesion in humans showed T cells, macrophages, dendritic cells and neutrophils, cytokines and chemokines but no B cells. The CSF analysis in patients with early neuroborreliosis showed a lymphocytic infiltrate with moderately increased proteinorachia and antibodies against $B$. burgdorferi. The lymphocytic pleocytosis is caused by the lymphocytes $\mathrm{B}$, as $B$. garinii may stimulate the monocytes in vitro to produce CXCL13, the lymphocytes B chemoatractant. The levels of C1q, C4, C3 and C3a are increased in the CSF but not in the plasma, suggesting that the inflammatory response is localized in the CSF (Rupprecht et al., 2007).

Lyme arthritis presents in two clinical forms: an acute arthritis, reproduced by the murine model and a prolonged arthritis that resembles rheumatoid arthritis (Steere and Angelis, 2006). The synovial biopsies in nontreated patients showed lymphocytic infiltrates, rare macrophages, dendritic and plasmatic cells associated with spirochetes and antigen deposits in the perivascular space. The spontaneous remission of an acute arthritis episode is immune mediated, but the spirochetes may persist in the absence of antibiotic therapy and cause recurrent episodes of arthritis. $10 \%$ of the patients with Lyme arthritis develop chronic synovitis. In studies from the '80s, these patients were presenting arthritis $>12$ months and responded to antibiotic therapy when it was initiated (Steere et al., 1987). In the following years, a second group of patients was identified, to whom arthritis was not responding to 3 months of antibiotic therapy (Steere and Angelis, 2006), and inflammation persisted in the absence of $B$. burgdorferi. These patients present high levels of TNF alpha, IL-1 beta and IFN gamma in the synovial liquid. Many theories have been proposed to explain the pathogenesis of refractory Lyme arthritis; the autoimmune theory is based on similarities between Lyme arthritis and rheumatoid arthritis (the presence of HLA-DRB1 molecules) (Steere et al., 2006).

Biopsies from the first cases of Lyme carditis showed myocardic infiltration with lymphocytes, plasmatic cells and macrophages. Murine carditis is characterized by bacterial infiltration of the conjunctive tissue around the aortic valve and the aorta at the heart base; the leucocytic infiltrate has a peak on the $15^{\text {th }}$ day of infection, with remission of carditis and spirochetal clearance after 30 days (Barthold et al., 1991).

Pathogenesis research in LB has passed into the genomic era and it is likely that functional genomics will shed more light on disease-inducing mechanisms of $B$. burgdorferi s.l. in the near future.

\section{CONCLUSIONS}

From the public health prospective, a better information on the etiology and epidemiology of $B$. burgdorferi, its interaction with the human host and disease pathogenesis, represents a key factor for a better approach to Lyme borreliosis of medical personnel.

\section{Acknowledgements}

The publication of this paper was supported from grant IDEI-PCCE CNCSIS 84, 7/2010 and from a project co-financed by E.S.F POSDRU $88 / 1.5 / \mathrm{S} / 56949$. The work of the author was done under the frame of EurNegVec COST Action TD1303.

\section{REFERENCES}

1. Alban PS, Johnson PW, Nelson DR (2000). Serumstarvation-induced changes in protein synthesis and morphology of Borrelia burgdorferi. Microbiology 146:119-127.

2. Anderson JF, Magnarelli LA (2008). Biology of ticks. Infect Dis Clin North Am 22(2):195-215.

3. Bankhead T, Chaconas G (2007). The role of VlsE antigenic variation in the Lyme disease spirochete: persistence through a mechanism that differs from other pathogens. Mol Microbiol 65(6):1547-1558.

4. Barthold SW, Persing DH, Armstrong AL, Peeples RA (1991). Kinetics of Borrelia burgdorferi dissemination and evolution of disease after intradermal inoculation of mice. Am J Pathol 139(2):263-273.

5. Bergström S, Noppa L, Gylfe A, Östberg Y (2002). Molecular and Cellular Biology of Borrelia burgdorferi sensu lato, P. 47-90. In: Gray JS, Kahl O, Lane RS, Stanek G (Eds). Lyme Borreliosis: Biology, Epidemiology and Control. Wallingford, CAB International. 
6. Bergstrom S, Zuckert WR (2010). Structure, function and biogenesis of the Borrelia cell envelope, p. 139-166. In: Samuels DS, Radolf JD (Eds.). Borrelia: Molecular Biology, Host Interaction, and Pathogenesis. Caister Academic, Norfolk, UK.

7. Briciu VT, Meyer F, Sebah D, Țățulescu DF, Coroiu G, Lupșe M, Carstina D, Mihalca AD, Hizo-Teufel C, Klier C, Huber I, Fingerle V (2014). Real-time PCR based identification of Borrelia burgdorferi sensu lato species in ticks collected from humans in Romania. Ticks Tick Borne Dis 5(5): 575581.

8. Brorson 0, Brorson SH (2006). An in vitro study of the activity of telithromycin against mobile and cystic forms of Borrelia afzelii. Infection 34:26-28.

9. Bunikis I, Denker K, Ostberg Y, Andersen C, Benz R, Bergström S (2008). An RND-type efflux system in Borrelia burgdorferi is involved in virulence and resistance to antimicrobial compounds. PLoS Pathog 4:e1000009.

10. Burgdorfer W, Barbour AG, Hayes SF, Benach JL, Grunwaldt E, Davis JP (1982). Lyme disease - a tickborne spirochetosis? Science 216 (4552): 1317-1319.

11. Cabello FC, Godfrey HP, Newman SA (2007). Hidden in plain sight: Borrelia burgdorferi and the extracellular matrix. Trends Microbiol 15(8):350-354.

12. Carroll JA, El-Hage N, Miller JC, Babb K, Stevenson B (2001). Borrelia burgdorferi RevA antigen is a surfaceexposed outer membrane protein whose expression is regulated in response to environmental temperature and pH. Infect. Immun 69:5286-5293.

13. Casjens S, Palmer N, van Vugt R, Huang WM, Stevenson B, Rosa P, et al. (2000). A bacterial genome in flux: the twelve linear and nine circular extrachromosomal DNAs in an infectious isolate of the Lyme disease spirochete Borrelia burgdorferi. Molecular Microbiology 35:490-516.

14. Casjens SR, Fraser-Liggett CM, Mongodin EF, Qiu WG, Dunn JJ, Luft BJ, et al. (2011) Whole genome sequence of an unusual Borrelia burgdorferi sensu lato isolate. J Bacteriol 193(6):1489-1490.

15. da Franca I, Santos L, Mesquita T, Collares-Pereira M, Baptista S, Vieira L, et al. (2005). Lyme borreliosis in Portugal caused by Borrelia lusitaniae?Clinical report on the first patient with a positive skin isolate. Wien Klin Wochenschr 117:429-432.

16. Dandache P, Nadelman RB (2008). Erythema migrans. Infect Dis Clin North Am 22(2):235-260.

17. Diza E, Papa A, Vezyri E, Tsounis S, Milonas I, Antoniadis A (2004). Borrelia valaisiana in cerebrospinal fluid. Emerg Infect Dis 10:1692-1693.

18. Embers ME, Barthold SW, Borda JT, Bowers L, Doyle L, Hodzic E, et al. (2012). Persistence of Borrelia burgdorferi in Rhesus Macaques following Antibiotic Treatment of Disseminated Infection. PLoS One 7(1):e29914.

19. Estrada-Peña A, Bouattour A, Camicas JL, Walker AR (2004). Ticks of domestic animals in the Mediterranean region, a guide to identification of species. Atalanta, Houten.

20. Fingerle V, Schulte-Spechtel U, Ruzic-Sabljic E, Leonhard S, Hofmann H, Weber K, et al. (2008). Epidemiological aspects and molecular characterization of Borrelia burgdorferi s.l. from southern Germany with special respect to the new species Borrelia spielmanii sp. nov. Int J Med Microbiol 298(3-4):279-290.

21. Franke J, Hildebrandt A, Dorn W. Exploring gaps in our knowledge on Lyme borreliosis spirochaetes-updates on complex heterogeneity, ecology, and pathogenicity (2013). Ticks Tick Borne Dis 4(1-2):11-25.

22. Fraser CM, Casjens S, Huang WM, Sutton GG, Clayton $\mathrm{R}$, Lathigra R, et al. (1997). Genomic sequence of a Lyme disease spirochaete, Borrelia burgdorferi. Nature 390:580-586.

23. Gern L (2008). Borrelia burgdorferi sensu lato, the agent of Lyme borreliosis: life in the wilds. Parasite 15:244-247.

24. Girschick HJ, Huppertz HI, Rüssmann H, Krenn V, Karch H (1996). Intracellular persistence of Borrelia burgdorferi in human synovial cells. Rheumatol Int 16(3):125-132.

25. Glatz M, Golestani M, Kerl H, Müllegger RR (2006). Clinical relevance of different IgG and IgM serum antibody responses to Borrelia burgdorferi after antibiotic therapy for erythema migrans: long-term follow-up study of 113 patients. Arch Dermatol 142: 862-868.

26. Hodzic E, Feng S, Freet KJ, Barthold SW (2003). Borrelia burgdorferi population dynamics and prototype gene expression during infection of immunocompetent and immunodeficient mice. Infect Immun 71(9):5042-5055.

27. Hodzic E, Feng S, Holden K, Freet KJ, Barthold SW (2008). Persistence of Borrelia burgdorferi following antibiotic treatment in mice. Antimicrob Agents Chemother 52(5):1728-1736.

28. Hunfeld KP, Ruzic-Sabljic E, Norris DE, Kraiczy P, Strle F (2006). Risk of culture-confirmed borrelial persistence in patients treated for erythema migrans and possible mechanisms of resistance. Int J Med Microbiol 22(296S1):233-241.

29. Ionita M, Mitrea IL, Pfister K, Hamel D, Silaghi C (2013). Molecular evidence for bacterial and protozoan pathogens in hard ticks from Romania. Vet Parasitol 196(1-2):71-76.

30. Jaulhac B, Heller R, Limbach FX, Hansmann Y, Lipsker D, Monteil H., et al. (2000). Direct molecular typing of Borrelia burgdorferi sensu lato species in synovial samples from patients with Lyme arthritis. J Clin Microbiol 38:1895-1900.

31. Johnson RC, Schmid GP, Hyde FW, Steigerwalt AG, Brenner DJ (1984). Borrelia burgdorferi sp. nov.: etiologic agent of Lyme disease. Int J Syst Bacteriol 34:496-497.

32. Kahl O, Gern L, Eisen L, Lane RS (2002). Ecological Research on Borrelia burgdorferi sensu lato: Terminology and Some Methodological Pitfalls, p. 29-46. In: Gray JS, Kahl O, Lane RS, Stanek G (Eds.) Lyme Borreliosis: Biology, Epidemiology and Control. CAB International.

33. Kalish RA, McHugh G, Granquist J, Shea B, Ruthazer R, Steere AC (2001). Persistence of immunoglobulin $M$ or immunoglobulin G antibody responses to Borrelia burgdorferi 10-20 years after active Lyme disease. Clin Infect Dis 33:780-785.

34. Kalmár Z, Mihalca AD, Dumitrache MO, Gherman CM, Magdaş C, Mircean V, Oltean M, Domsa C, Matei IA, 
Marcutan DI, Sándor AD, D’Amico D, Pastiu A, Györke A, Gavrea R, Marosi B, Ionica, A, Burkhardt E, Toriay H, Cozma V (2013). Geographical distribution and prevalence of Borrelia burgdorferi genospecies in questing Ixodes ricinus from Romania: a countrywide study. Ticks Tick Borne Dis 4(5): 403-408.

35. Keller A, Graefen A, Ball M, Matzas M, Boisguerin V, Maixner F, et al. (2012) New insights into the Tyrolean Iceman's origin and phenotype as inferred by wholegenome sequencing. Nat Commun 3:698.

36. Kraiczy P, Skerka C, Kirschfink M, Zipfel PF, Brade V (2001). Mechanism of complement resistance of pathogenic Borrelia burgdorferi isolates. Int Immunopharmacol 1(3):393-401.

37. Lünemann JD, Zarmas S, Priem S, Franz J, Zschenderlein R, Aberer E, et al. (2001). Rapid typing of Borreliaburgdorferi sensu lato species in specimens from patients with different manifestations of Lyme borreliosis. J Clin Microbiol 39(3):1130-1133.

38. MacDonald AB (2006). A life cycle for Borrelia spirochetes? Med Hypotheses 67:810-818.

39. Maraspin V, Ruzic-Sabljic E., Strle F (2006). Lyme borreliosis and Borrelia spielmanii. Emerg. Infect. Dis 12:1177.

40. Margos G, Vollmer SA, Cornet M, Garnier M, Fingerle V, Wilske B, et al. (2009). A new Borrelia species defined by multilocus sequence analysis of housekeeping genes. Appl Environ Microbiol 75:5410-5416.

41. Miller JC, Bono JL, Babb K, El-Hage N, Casjens S, Stevenson B (2000). A second allele of eppA in Borrelia burgdorferi strain B31 is located on the previously undetected circular plasmid cp9-2. J. Bacteriol 182:6254-6258.

42. Moriarty TJ, Norman MU, Colarusso P, Bankhead T, Kubes P, Chaconas G (2008). Real-time high resolution 3D imaging of the lyme disease spirochete adhering to and escaping from the vasculature of a living host. PLoS Pathog 4(6):e1000090.

43. Motaleb MA, Corum L, Bono JL, Elias AF, Rosa P, Samuels DS, Charon NW (2000). Borrelia burgdorferi periplasmic flagella have both skeletal and motility functions. Proc Natl Acad Sci USA 97(20):10899-10904.

44. Nadelman RB, Wormser GP (2007). Reinfection in patients with Lyme disease. Clin Infect Dis 45:1032-1038.

45. Radolf JD, Bourell KW, Akins DR, Brusca JS, Norgard MV (1994). Analysis of Borrelia burgdorferi membrane architecture by freeze-fracture electron microscopy. Journal of Bacteriology 176:21-31.

46. Radolf JD, Caimano MJ, Stevenson B, Hu LT (2012). Of ticks, mice and men: understanding the dual-host lifestyle of Lyme disease spirochaetes. Nat Rev Microbiol 10(2):8799.

47. Rijpkema SG, Tazelaar DJ, Molkenboer MJ, Noordhoek GT, Plantinga G, Schouls LM, Schellekens JF (1997). Detection of Borrelia afzelii, Borrelia burgdorferi sensu stricto, Borrelia garinii and group VS116 by PCR in skin biopsies of patients with erythema migrans and acrodermatitis chronica atrophicans. Clin Microbiol Infect 3:109-116.
48. Rudenko N, Golovchenko M, Grubhoffer L, Oliver JH (2011). Updates on Borrelia burgdorferi sensu lato complex with respect to public health. Ticks Tick Borne Dis 2(3):123-128.

49. Rudenko N, Golovchenko M, Mokracek A, Piskunova N, Ruzek D, Mallatova N, et al. (2008). Detection of Borrelia bissettii in cardiac valve tissue of a patient with endocarditis and aortic valve stenosis in the Czech Republic. J Clin Microbiol 46:3540-3543.

50. Rudenko N, Golovchenko M, Růzek D, Piskunova N, Mallátová N, Grubhoffer L (2009). Molecular detection of Borrelia bissettii DNA in serum samples from patients in the Czech Republic with suspected borreliosis. FEMS Microbiol Lett 292(2):274-281.

51. Rupprecht T, Kirschning C, Popp B, Kastenbauer S, Fingerle V, Pfister H, et al. (2007). Borrelia garinii induces CXCL13 production in human monocytes through Tolllike receptor 2. Infect Immun 75(9):4351-4356.

52. Sapi E, Bastian SL, Mpoy CM, Scott S, Rattelle A, Pabbati N, et al. (2012). Characterization of biofilm formation by Borrelia burgdorferi in vitro. PLoS One 7(10):e48277.

53. Sapi E, Kaur N, Anyanwu S, Luecke DF, Datar A, Patel S, et al. (2011). Evaluation of in-vitro antibiotic susceptibility of different morphological forms of Borrelia burgdorferi. Infect Drug Resist 4:97-113.

54. Schutzer SE, Fraser-Liggett CM, Casjens SR, Qiu WG, Dunn JJ, Mongodin EF, et al. (2011). Whole genome sequences of thirteen isolates of Borrelia burgdorferi. J. Bacteriol 193:1018-1020.

55. Schutzer SE, Fraser-Liggett CM, Qiu WG, Kraiczy P, Mongodin EF, Dunn JJ, et al. (2012). Whole-genome sequences of Borrelia bissettii, Borrelia valaisiana, and Borrelia spielmanii. J Bacteriol 194(2):545-546.

56. Steere AC, Angelis SM (2006). Therapy for Lyme arthritis: strategies for the treatment of antibiotic-refractory arthritis. Arthritis Rheum 54(10):3079-3086.

57. Steere AC, Klitz W, Drouin EE, Falk BA, Kwok WW, Nepom GT, et al. (2006) Antibiotic-refractory Lyme arthritis is associated with HLA-DR molecules that bind a Borrelia burgdorferi peptide. J Exp Med 203(4):961-971.

58. Steere AC, Schoen RT, Taylor E (1987). The clinical evolution of Lyme arthritis. Ann Intern Med 107(5):725731.

59. Straubinger RK, Summers BA, Chang YF, Appel MJ (1997). Persistence of Borrelia burgdorferi in experimentally infected dogs after antibiotic treatment. Journal of Clinical Microbiology 35:111-116.

60. Strle F, Picken RN, Cheng Y, Cimperman J, Maraspin V, Lotric- Furlan S, Ruzic-Sabljic E, Picken MM (1997). Clinical findings for patients with Lyme borreliosis caused by Borrelia burgdorferi sensu lato with genotypic and phenotypic similarities to strain 25015. Clinical Infectious Disease 25: 273-280.

61. von Lackum K, Stevenson B (2005). Carbohydrate utilization by the Lyme borreliosis spirochete, Borrelia burgdorferi. FEMS Microbiol. Lett 243:173-179.

62. Weis JJ, Bockenstedt LK (2010). Host response., p. 413441. In: Samuels DS, Radolf JD (Eds.). Borrelia: Molecular 
Biology, Host Interaction, and Pathogenesis. Caister Academic, Norfolk, UK.

63. Wilske B, Busch U, Eiffert H, Fingerle V, Pfister HW, Rossler D, et al. (1996). Diversity of OspA and OspC among cerebrospinal fluid isolates of Borrelia burgdorferi sensu lato from patients with neuroborreliosis in Germany. Med Microbiol Immunol 184:195-201.

64. Wilske B, Fingerle V, Schulte-Spechtel U (2007). Microbiological and serological diagnosis of Lyme borreliosis. FEMS Immunol Med Microbiol 49:13-21.
65. Yang X, Izadi H, Coleman AS, Wang P, Ma Y, Fikrig E, Anguita J, Pal U (2008). Borrelia burgdorferi lipoprotein BmpA activates pro-inflammatory responses in human synovial cells through a protein moiety. Microbes Infect 10:1300-1308.

66. Zhang JR and Norris SJ (1998). Kinetics and in vivo induction of genetic variation of $v l s E$ in Borrelia burgdorferi. Infection and Immunity 66:3689-3697. 